\title{
Induction of immunological memory response by vaccination with TM4SF5 epitope-CpG-DNA-liposome complex in a mouse hepatocellular carcinoma model
}

\author{
SANGHOON KWON ${ }^{1}$, DONGBUM KIM ${ }^{1}$, BYOUNG KWON PARK ${ }^{2}$, GUANG WU $^{1}$, MIN CHUL PARK ${ }^{2}$, \\ YANG-WHA HA ${ }^{3}$, HYUNG-JOO KWON ${ }^{1,2}$ and YOUNGHEE LEE ${ }^{3}$ \\ ${ }^{1}$ Center for Medical Science Research and ${ }^{2}$ Department of Microbiology, College of Medicine, Hallym University, Gangwon; \\ ${ }^{3}$ Department of Biochemistry, College of Natural Sciences, Chungbuk National University, Chungbuk, Republic of Korea
}

Received August 29, 2012; Accepted October 8, 2012

DOI: $10.3892 /$ or.2012.2130

\begin{abstract}
The innovation of a peptide vaccine strategy may contribute to the development of efficacious and convenient cancer vaccines. Recently, we formulated an efficacious peptide vaccine without carriers using the natural phosphodiester bond CpG-DNA and a special liposome complex [Lipoplex(O)]. The peptide vaccine targeting a tumor antigen, transmembrane 4 superfamily member 5 protein (TM4SF5), was confirmed to have preventive and therapeutic effects in a mouse hepatocellular carcinoma (HCC) model. In this study, we demonstrated that the isotype-switched $\left(\operatorname{IgM}-\operatorname{IgD}^{-}\right)$ $B$ cell population increased after immunization and that the functional memory response persisted for at least 70 days after the final immunization of mice. Delayed implantation of BNL-HCC cells significantly induced the peptide-specific IgG2a production in the immunized mice. Accordingly, tumor growth was inhibited and the survival rate increased. These results suggest that our peptide vaccine induces memory response, which is essential for cancer vaccine application.
\end{abstract}

\section{Introduction}

Although cancer is currently one of the most leading causes of mortality, prevention and therapy remains inadequate. Traditional antitumor approaches including surgery, radiotherapy and chemotherapy have various adverse effects derived from a lack of specificity; they also induce severe

Correspondence to: Dr Younghee Lee, Department of Biochemistry, Chungbuk National University, Cheongju 361-763, Republic of Korea E-mail: yhl4177@cbnu.ac.kr

Dr Hyung-Joo Kwon, Department of Microbiology, College of Medicine, Hallym University, Gangwon 200-702, Republic of Korea E-mail: hjookwon@hallym.ac.kr

Key words: peptide vaccine, $\mathrm{CpG}$, liposome, prophylaxis, memory, TM4SF5, hepatocellular carcinoma, animal model damage or dysfunction of normal cells (1). Immunotherapy including cancer vaccines, which is designed to modulate immune responses of patients to induce specific removal of cancer cells has gained increasing attention (2). For efficacious function of cancer vaccines without side effects, the selection of proper tumor-specific antigens or tumor-associated antigens as a target is important $(3,4)$. To stimulate immune responses to selected tumor antigens, antigenic sources such as peptides, proteins, inactivated tumor cells and DNAs may be used (5). Among the antigens, peptides are the easiest to produce and to monitor immune responses. Therefore, the innovation of a peptide vaccine strategy with enhanced immunostimulatory efficacy may greatly contribute to the development of cancer vaccines (6).

CpG-DNA, a sequence containing unmethylated $\mathrm{CpG}$ dinucleotides flanked by specific base sequences, has immunostimulatory activities (7-9): activation of antigenpresenting cells, induction of Th1-biased immune responses and immunoglobulin (Ig) isotype switching (10-12). Although a number of researchers use phosphorothioate-modified CpG-DNA (PS-ODN) due to its nuclease resistance and efficient uptake into cells, PS-ODN induces PS-ODN-specific IgM production and backbone-related side effects such as transient lymphadenopathy, lymphoid follicle destruction and arthritis (13-16). Therefore, we isolated the natural phosphodiester bond CpG-DNA [PO-ODN, MB-ODN 4531(O)] from Mycobacterium bovis genomic DNA and confirmed its stimulating activity to induce optimal innate immune responses (17). The activities of CpG-DNA as a potent adjuvant are enhanced through encapsulation in liposomes $(18,19)$. When the effect of the lipid composition on the activity of the phosphodiester bond CpG-ODN was investigated in human and mouse immune cells in vitro, DOPE:CHEMS (1:1 ratio) proved to have a superior effect (20). Furthermore, encapsulation of the phosphodiester bond CpG-DNA in a DOPE:CHEMS (1:1 ratio) complex [Lipoplex $(\mathrm{O})$ ] enhanced adjuvant activity in mice when proteins were used as antigens (21). Therefore, we applied this formulation to peptides and discovered that complexes of the $\mathrm{B}$ cell epitope peptide and Lipoplex $(\mathrm{O})$ significantly induced peptide-specific $\mathrm{Ig} G$ production $(20,22)$. 
To validate the application of our novel strategy to cancer vaccines, we used the peptide TM4SF5R2-3 targeting the transmembrane 4 superfamily member 5 protein (TM4SF5) as a tumor-specific antigen. TM4SF5 has been implicated in hepatocellular carcinoma (HCC) (23). Immunization with the peptide vaccine composed of TM4SF5R2-3 and Lipoplex $(\mathrm{O})$ induced functional antitumor effects in vivo; preventive and therapeutic effects against tumor formation of implanted HCC cells in mice (24).

In the development of a cancer vaccine, induction of a memory response by the vaccination is an essential prerequisite for practical application (2). In this study, we examined tumor formation in the mice immunized with the TM4SF5R2-3 peptide vaccine after delayed challenge of HCC cells and discovered that the peptide vaccine induced a functional memory response.

\section{Materials and methods}

Synthesis of CpG-DNA and a B cell epitope peptide. MB-ODN 4531(O), a natural phosphodiester bond CpG-DNA, consists of 20 bases containing three $\mathrm{CpG}$ motifs (underlined): AGCAGCGTTCGTGTCGGCCT(17).The B cell epitope peptide of human TM4SF5 (TM4SF5R2-3, ${ }^{138}$ NRTLWDRCEAPPRV ${ }^{151}$ ) was selected and produced as previously described (24).

Preparation of B cell epitope and CpG-DNA co-encapsulated in DOPE:CHEMS complexes. Liposome complexes consisting of B cell epitope and CpG-DNA [MB-ODN 4531(O)] co-encapsulated with DOPE:CHEMS were prepared as previously reported (20). Briefly, DOPE and CHEMS were mixed in 10\% ethanol at a molar ratio of 1:1, evaporated with nitrogen gas to produce a solvent-free lipid film and resuspended in a mixture containing equal volumes of water-soluble MB-ODN $4531(\mathrm{O})(50 \mu \mathrm{g})$ and peptide $(50 \mu \mathrm{g})$, followed by vigorous stirring at room temperature for $30 \mathrm{~min}$. After adjusting the $\mathrm{pH}$ to 7.0, the peptide and Lipoplex $(\mathrm{O})$ complex was sonicated lightly for $30 \mathrm{sec}$ with a sonicator (Sonifier 450; Branson Ultrasonics). After the complex was filtered with a $0.22 \mu \mathrm{m}$ filter, it was freeze-thawed 3 times with liquid nitrogen.

Antigen-specific Ig ELISA assay. Mouse sera were achieved by orbital bleeding. To determine the amounts and titers of total IgG, 96-well immunoplates (Nalge Nunc International) were coated with $5 \mu \mathrm{g} / \mathrm{ml}$ of each peptide and then blocked with $0.05 \%$ of Tween-20 in PBS (PBST) containing 1\% BSA. Total IgG levels were measured as previously described (20).

FACS analysis. The mice were immunized on 3 occasions at 10-day intervals and their splenocytes were obtained 10 days after the last immunization. The expression of IgM, IgD, B220 and/or CD138 was analyzed with a FACS Aria II flow cytometer (BD Biosciences). Splenocytes were washed with PBS containing $0.1 \%$ bovine serum albumin and incubated for $20 \mathrm{~min}$ at $4^{\circ} \mathrm{C}$ with $10 \mu \mathrm{g} / \mathrm{ml}$ of anti-Fc $\gamma \mathrm{RII} / \mathrm{III}$ antibody (BD Biosciences) to block Fc receptors. After blocking, the cells were incubated with the indicated antibodies (IgM-FITC, IgD-PE, B220-Pacific Blue and CD138-APC; BD Biosciences) for $1 \mathrm{~h}$ at $4^{\circ} \mathrm{C}$. FACS data were analyzed with the aid of WinMDI 2.8 FACS software.
Cell culture. The mouse hepatoma cell line BNL-HCC was obtained from ATCC. BNL-HCC is a chemically transformed mouse liver cell line derived from the normal BALB/c embryonic liver cell line BNL CL2 (25). The cells were cultured in a DMEM medium containing 10\% FBS, 25 mM HEPES, $100 \mathrm{U} / \mathrm{ml}$ of penicillin and $100 \mu \mathrm{g} / \mathrm{ml}$ of streptomycin at $37^{\circ} \mathrm{C}$ in an atmosphere of $95 \%$ air and $5 \% \mathrm{CO}_{2}$.

Hepatocellular carcinoma mouse model. We purchased four-week-old male BALB/c $\left(\mathrm{H}-2^{\mathrm{b}}\right)$ mice from Central Lab. Animal, Inc. Mice were maintained under specific-pathogenfree conditions in a controlled environment $\left(20-25^{\circ} \mathrm{C}, 32-37 \%\right.$ humidity). All animal procedures performed in this study were in accordance with the recommendations in the Guide for the Care and Use of Laboratory Animals of the National Veterinary Research and Quarantine Service of Korea. The protocol was approved by the Institutional Animal Care and Use Committee of Hallym University (permit no. Hallym 2010-82). On 3 occasions at 10-day intervals, the mice were injected intraperitoneally with $50 \mu \mathrm{g}$ of TM4SF5R2-3 peptide supplemented with $50 \mu \mathrm{g}$ of MB-ODN4531(O) encapsulated in the DOPE:CHEMS complex (200 $\mu \mathrm{l} /$ mouse). As a control, mice were injected with PBS or $50 \mu \mathrm{g}$ of TM4SF5R2-3 peptide encapsulated in the DOPE:CHEMS complex. Seventy days after the third immunization, the mice were inoculated subcutaneously in the right dorsal flank with PBS or $5 \times 10^{6}$ of BNL-HCC cells in a 50\% Matrigel solution (HBSS/ Matrigel, 1:1 v/v; BD Biosciences) as previously described (26). The size of the tumor was measured at 5-day intervals with calipers in 3 dimensions, and tumor volumes were calculated as width ${ }^{2} \mathrm{x}$ length $/ 2$. The mice were sacrificed on the indicated days after the tumor cell implantation and the tumors were surgically excised and weighed. The survival rate was recorded for 90 days after tumor cell implantation. The mice were sacrificed under Zoletil $50+$ Rompun anesthesia and all efforts were made to minimize suffering. Mice were sacrificed when the tumor size reached $2,000 \mathrm{~mm}^{3}$ or the mice lost $>20 \%$ of initial body weight to minimize suffering from a large tumor burden.

Statistics. Results are expressed as the means \pm standard deviation. Statistical significance between the 2 samples was performed using the Student's t-test. A P-value of $<0.05$ was considered to indicate a statistically significant difference. A survival analysis was performed using the Kaplan-Meier method and compared with a log-rank test.

\section{Results}

Increase in the putative memory $B$ cell population in the mice immunized with a complex of the TM4SF5R2-3 peptide and Lipoplex $(O)$. We previously confirmed the prophylactic effect of a peptide vaccine composed of the TM4SF5R2-3 peptide and Lipoplex $(\mathrm{O})$ complex in an HCC model (23). In this study, we immunized mice with the peptide vaccine 3 times at 10-day intervals and directly challenged the mice with hTM4SF5-expressing BNL-HCC cells on Day 30. Immunological memory is a critical feature of the adaptive immune response and memory function of humoral immunity involves the development of memory B cells. As memory 
A

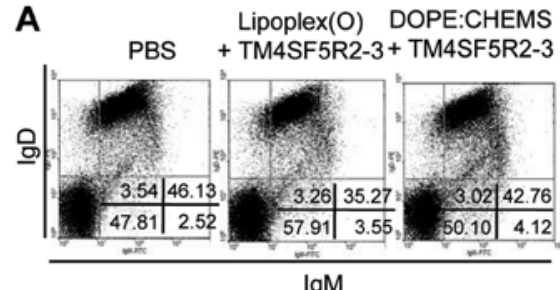

$\lg M$

B PBS

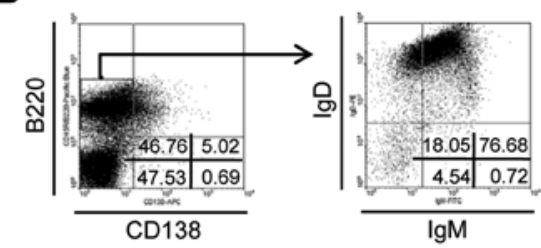

Lipoplex(O)

+ TM4SF5R2-3

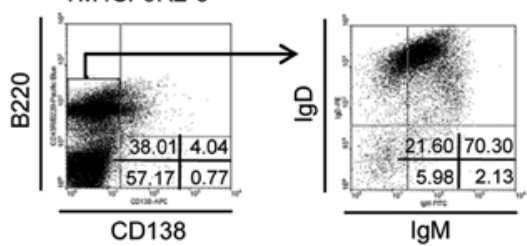

DOPE:CHEMS

+ TM4SF5R2-3

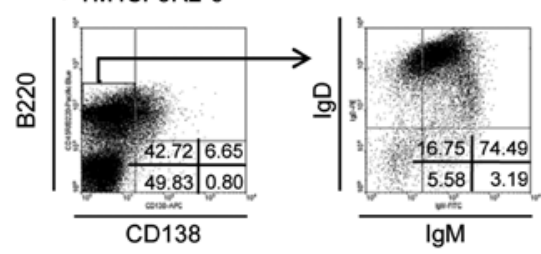

Figure 1. Increase in the isotype-switched B cell population by immunization with the TM4SF5R2-3 peptide and Lipoplex $(\mathrm{O})$ complex. The BALB/c mice $(n=3)$ were immunized on 3 occasions at 10-day intervals and their splenocytes were obtained 10 days after the last immunization. The expression of IgM, IgD, B220 and/or CD138 was analyzed by flow cytometry. (A) Splenocytes were labeled with IgM-FITC and IgD-PE. (B) Splenocytes were 4 colorstained with IgM-FITC, IgD-PE, B220-Pacific Blue and CD138-APC. B220 CD138- population was first gated and the expression of $\operatorname{IgM}$ and $\operatorname{IgD}$ was then monitored. FACS data were analyzed with the aid of WinMDI 2.8 FACS software. These are representative data from 3 mice/group.

B cells are considered a subpopulation of isotype-switched B cells (B220+IgD-IgM-CD138-) (27-29), we analyzed the surface marker expression of spleen cells from 3 different experimental groups of mice ( 8 mice/group) 10 days after the last immunization. The population of $\operatorname{IgD}^{-} \operatorname{IgM}^{-}$cells was larger in the splenocytes from the mice immunized with a complex of TM4SF5R2-3 peptide and Lipoplex $(\mathrm{O})$ compared with the other 2 control groups (57.91 vs. 47.81 or 50.10) (Fig. 1A). For a detailed analysis, we gated a $\mathrm{B} 220^{+} \mathrm{CD} 138^{-}$cell population and then analyzed the expression of $\operatorname{IgD}$ and $\operatorname{IgM}$ (Fig. 1B). The $\mathrm{B}^{2} 20^{+} \mathrm{CD}^{-138}{ }^{-} \mathrm{IgD}^{-} \mathrm{IgM}^{-}$cell population was larger in the mice immunized with the TM4SF5R2-3 peptide and Lipoplex $(\mathrm{O})$ complex compared to the control mouse group immunized with PBS or the TM4SF5R2-3 peptide and DOPE:CHEMS (5.98 vs. 4.54 and 5.58). Therefore, we predicted a memory response of our vaccine and performed further experiments to confirm whether the long-lasting memory response protects mice from delayed challenge of cancer cells.
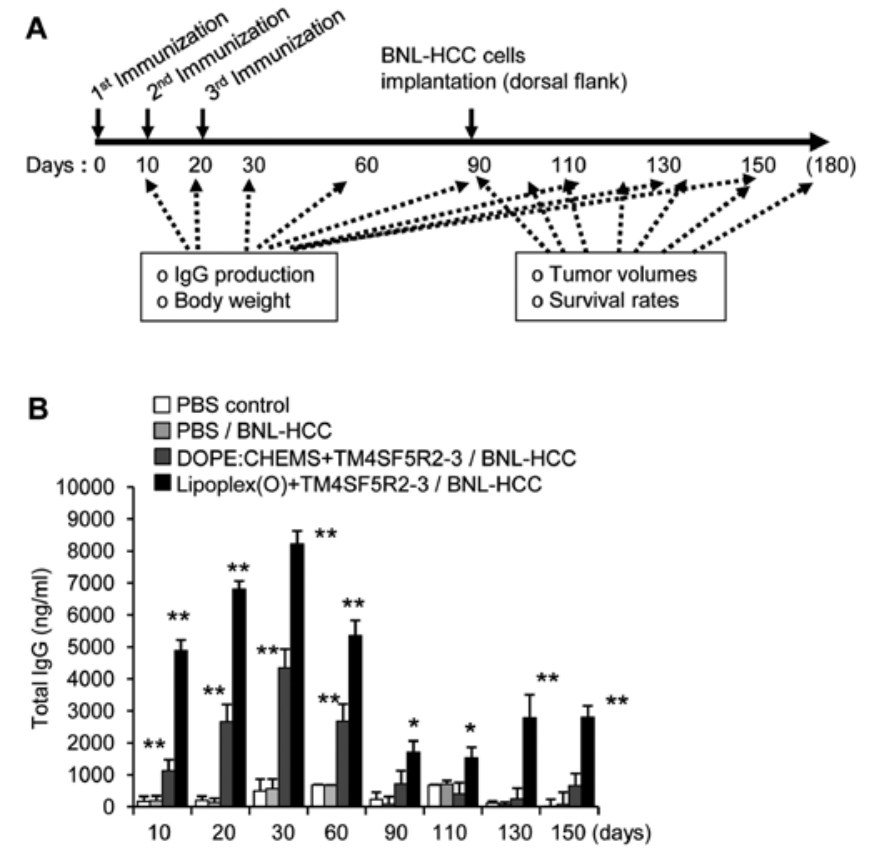

Figure 2. Production of IgG by immunization with the TM4SF5R2-3 peptide and Lipoplex(O) complex. (A) Experimental schedule and parameters used to analyze the mouse phenotypes. BALB/c mice were immunized with the TM4SF5R2-3 peptide and Lipoplex $(\mathrm{O})$ complex with a 10-day interval ( $\mathrm{n}=8 /$ group). On Day 90, the mice were challenged with BNL-HCC cells and the properties of the mice were monitored. (B) Amount of IgG during the experimental periods. The sera were collected and titers of the peptidespecific total IgG were assayed with an ELISA kit. These experiments were performed 2 times with similar results. ${ }^{*} \mathrm{P}<0.05,{ }^{* *} \mathrm{P}<0.01$ (vs. PBS control).

Production of $\operatorname{Ig} G$ by delayed implantation of cancer cells in the mice immunized with the TM4SF5R2-3 peptide and Lipoplex $(O)$ complex. The entire experimental schedule is depicted in Fig. 2A. To determine whether the state of memory is induced by a re-encounter of the antigens, we challenged the immunized mice with BNL-HCC cells 70 days after the third immunization (on Day 90) and checked $\mathrm{IgG}$ production and tumor formation (Fig. 2A). As a negative control, two groups of mice were immunized with PBS or TM4SF5R2-3 peptide encapsulated in DOPE:CHEMS and then implanted with BNL-HCC cells. The highest amount of TM4SF5R2-3-specific IgG in the vaccinated mice was detected on Day 30 (Fig. 2B). The amount of IgG decreased thereafter but remained significantly higher until Day 90 in the immunized mice compared to the control mouse group. A significant amount of antibodies was also observed in the mice immunized with TM4SF5R2-3 peptide encapsulated in DOPE:CHEMS. However, when we implanted BNL-HCC cells into the mice, the amount of IgG significantly increased again only in the mice immunized with the TM4SF5R2-3 peptide and Lipoplex(O) complex (Fig. 2B). This implies that CpG-DNA may be essential for the induction of a memory response.

Prophylactic efficacy of the vaccine against tumor formation of HCC cells implanted in mice. We examined the physical phonotype of mice after challenging them with BNL-HCC cells for 60 days. Based on tumor size (Fig. 3A), tumor volume (Fig. 3B) and tumor weight (Fig. 3C), tumor formation was 


\section{A}
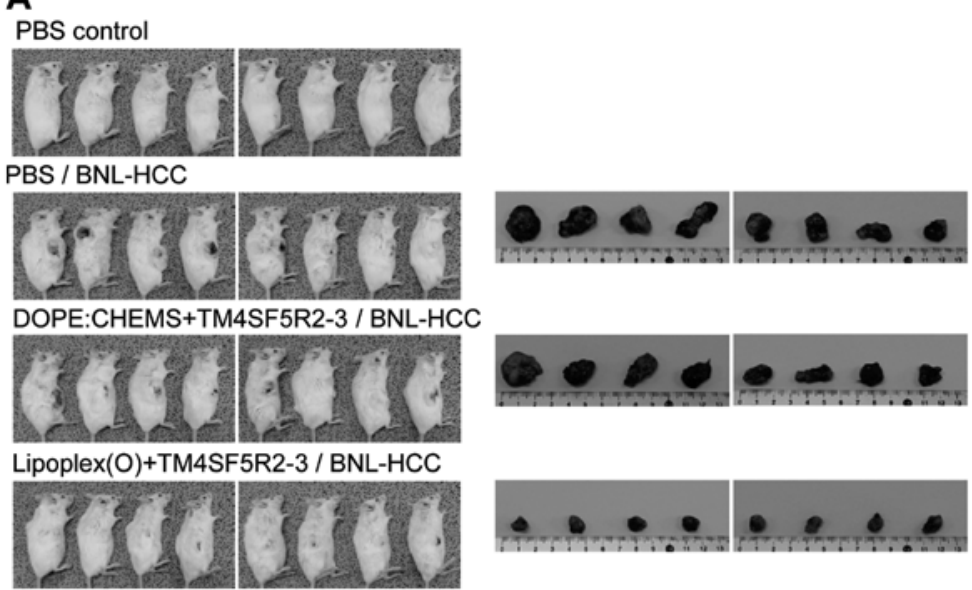

B

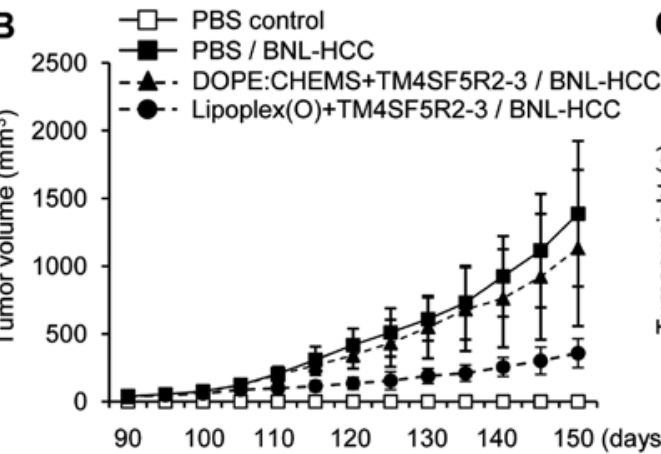

C
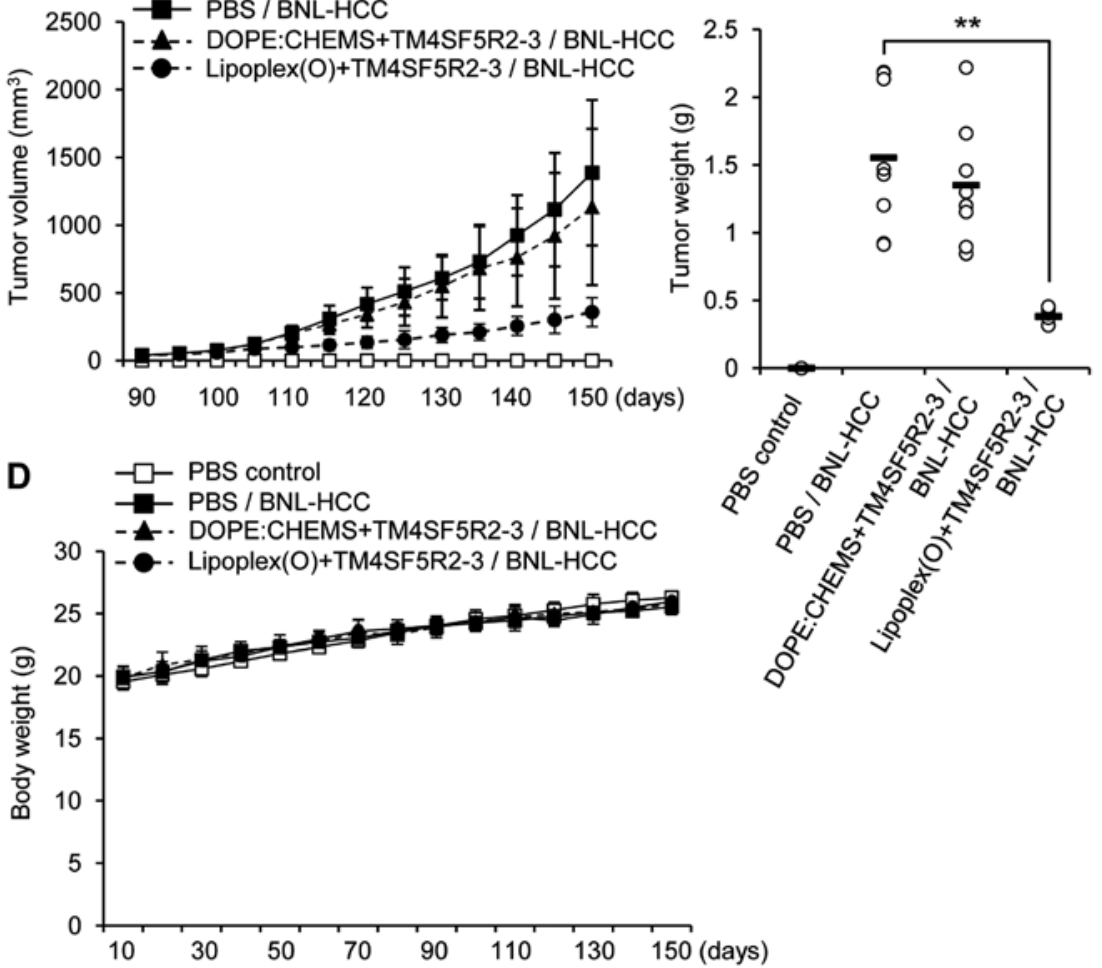

Figure 3. Memory response of the vaccine containing the TM4SF5R2-3 peptide and Lipoplex(O) complex in HCC implanted mice. BALB/c mice were immunized with a complex of TM4SF5R2-3 peptide and Lipoplex $(\mathrm{O})$ or indicated combinations. The immunized mice were implanted with BNL-HCC cells ( $\mathrm{n}=8$ /group) on the 90th day after the first immunization. Tumor formation in mice implanted with BNL-HCC cells was inhibited by vaccination with the TM4SF5R2-3 peptide and Lipoplex(O) complex. (A) Macroscopic appearance of HCC tumor tissues. (B) Tumor volumes were calculated as (length x width $\left.{ }^{2}\right) / 2$. (C) Tumor growth was measured by tumor weight. ${ }^{* *} \mathrm{P}<0.01$. (D) Body weight was measured at the indicated time intervals.

greatly inhibited in the mice immunized with the TM4SF5R2-3 peptide and Lipoplex $(\mathrm{O})$ complex. Immunization did not affect the body weight of the mice during the experiment, suggesting that there was no significant side effects (Fig. 3D). Slight decreases in the tumor volume and tumor weight were detected in the mice immunized with the TM4SF5R2-3 peptide encapsulated in DOPE:CHEMS without CpG-DNA suggesting a partial tumor suppressive effect.

Enhanced survival of the immunized mice in response to delayed challenge of HCC cells. To further evaluate the prophylactic efficacy of the vaccine, we assessed the survival rate of the mice challenged with BNL-HCC cells until Day 180
(3 months after implantation). The unimmunized control mice challenged with BNL-HCC cells were sacrificed by Day 170 (Fig. 4). In contrast, $75 \%$ of the mice immunized with TM4SF5R2-3 peptide and Lipoplex(O) survived until Day 180. Survival of the mice immunized with TM4SF5R2-3 peptide encapsulated with DOPE:CHEMS was also enhanced, which is in accordance with the lower tumor growth compared to the PBS control mice (Fig. 3); however all of the mice were sacrificed by day 180 . Therefore, only the vaccine composed of TM4SF5R2-3 peptide and Lipoplex $(\mathrm{O})$ demonstrated a prominent long-lasting prophylactic effect when we performed a cancer cell challenge experiment $\sim 2$ months after the final immunization. 


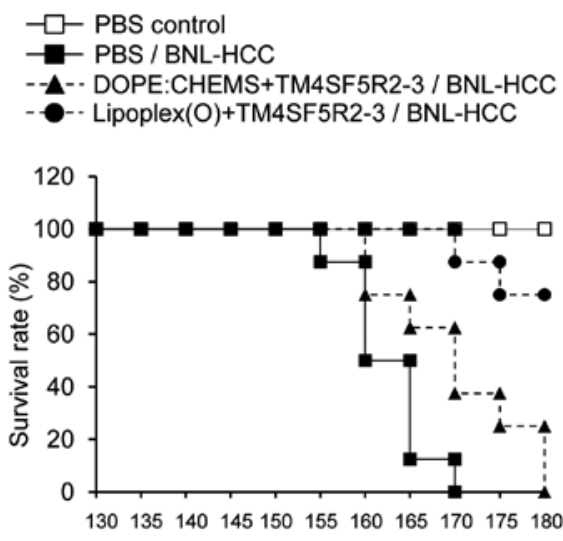

Days after BNL-HCC implantation

Figure 4. Survival rate of tumor-bearing mice. BALB/c mice were immunized with the TM4SF5R2-3 peptide and Lipoplex(O) complex or indicated combinations ( $\mathrm{n}=8$ /group). BNL-HCC cells were implanted in mice 70 days after the third vaccination (Day 90) and the survival rate was recorded for another 90 days.

\section{Discussion}

The immune system in our body recognizes antigens and coordinates specific immune responses against them through multi-cellular cooperation mainly involving antigen-presenting, $\mathrm{B}$ and $\mathrm{T}$ cells (1). When the antigens are proteins, usage of synthetic peptides rather than the whole proteins offers several advantages: They are easy to produce promptly and their cost is much lower. Peptides bind the B cell receptor and major histocompatibility (MHC) molecules as B- and T-cell epitopes, by which they induce and regulate immune responses. Therefore, peptide vaccines have the potential to be widely used in cancers and other infectious diseases $(6,30,31)$. However, the weak immunogenicity of peptides limits their application as a vaccine. Therefore, it is necessary to maximize the efficacy of peptide-driven immune responses. Recently, we developed a powerful strategy to induce the production of epitope-specific antibodies using peptides as an antigen $(20,21)$. To magnify the immune responses, we utilized Lipoplex $(\mathrm{O})$, comprised of natural CpG-DNA and a specific liposome complex as an adjuvant. We previously applied this strategy as a cancer vaccine (24) and we further evaluated the peptide vaccine in the context of the memory function.

Cancer vaccines require the induction of active tumorspecific immune responses without harming normal cells. The tumor-specific immune responses may prevent tumor formation (prophylactic vaccine) and/or treat established tumors in patients (therapeutic vaccine). The expression of TM4SF5 at the mRNA level has been reported in several types of human cancers including pancreatic cancer, soft tissue sarcoma, gastric cancer, carcinoma of the papilla vateri and colon cancer (32). The overexpression of TM4SF5 at the protein level was found by immunohistochemical staining in 7 out of $9 \mathrm{HCC}$ tissues, whereas normal liver tissues did not express TM4SF5 (23). Therefore, TM4SF5 may be an effective target for an HCC vaccine as a tumor specific antigen $(33,34)$. Previously, we confirmed that the monoclonal antibody produced using our strategy had a growth-inhibitory effect on human and mouse HCC cell lines (Huh-7 and BNL-HCC) expressing the antigen and that the monoclonal antibody may detect TM4SF5 in tumor tissues derived from an HCC mouse model $(20,23)$. Furthermore, the peptide vaccine composed of TM4SF5R2-3 peptide and Lipoplex $(\mathrm{O})$ induced prophylactic and therapeutic effects against tumor formation of implanted HCC cells in mice without prominent side effects (24).

In addition to the specificity of immune responses against tumors, cancer vaccines should induce immunological memory to suppress the recurrence of cancers (2). A number of vaccine approaches have revealed efficacy in murine cancer models; however they are ineffective or have limited efficacy in patients (2). In this study, we investigated whether our peptide vaccine induces memory response in mice. While it is difficult to define the exact events in vivo leading to the enhancement of immune responses, the effect of vaccine-induced protection against infection and disease appears to be correlated with the ability to induce long-term memory B cells and the production of specific antibodies (35). Therefore, we first performed a population analysis on splenocytes from the mice and discovered a slight increase in the isotype-switched $B$ cell population (B220+CD138-IgD-IgM-), which presumably includes memory B cells (Fig. 1). We then analyzed the amounts of epitopespecific antibodies for 150 days and observed that a significant amount of epitope-specific antibodies remained on Day 90 (70 days after the last immunization) and the level increased after the implantation of the HCC cells in the vaccinated mice (Fig. 2). To further evaluate the memory function, we examined the phenotypes of HCC-implanted mice and observed that the tumor growth was inhibited in the vaccinated mice, based on the tumor volume, tumor weight and survival of mice (Figs. 3 and 4). Taken together, these results indicate that our vaccine has an immunological memory response lasting at least 70 days after the last immunization. To further investigate the long-term memory response induced by this vaccine, the examination period must be extended in future studies.

The mechanisms involved in the induction of a memory response remain unclear. According to a recent influenza vaccine study, early $\mathrm{CD} 4^{+} \mathrm{T}$ cells appear to be required for longterm memory (36). However, there are controversial reports suggesting that memory $\mathrm{B}$ cells persist in mice deprived of a $\mathrm{T}$ cell population and that a unique $\mathrm{IgG}$ memory $\mathrm{B}$ cell niche is important for memory $(37,38)$. Previously, we confirmed that specific CD4 T cells and MHC molecules are necessary for antibody production induced by our strategy despite that we used only B cell epitope without any carrier (20). Therefore, it is possible that our system requires $\mathrm{T}$ cells for the memory response. Contribution of toll-like receptor (TLR) agonists to memory B cell function has also been documented $(27,39)$. CpG-DNA, a TLR agonist, was recently reported as an effective adjuvant for cancer vaccines inducing long-term antitumor activity using irradiated tumor cells and proteins as an antigen $(40,41)$. Liposomes are known to enhance antibody production and cytotoxic T lymphocyte (CTL) responses (42-44). Furthermore, the activities of CpG-DNA are reportedly enhanced by the encapsulation in liposomes $(18,19)$. Therefore, the cancer vaccine composed of the TM4SF5R2-3 peptide and Lipoplex $(\mathrm{O})$ used in this study may be powerful in inducing a short-term immune response as well as a long-lasting memory response. 


\section{Acknowledgements}

This study was supported by a grant from the Hallym Research Fund (HRF-201203-011) and grants from the National Research Foundation (2012R1A2A2A01009887, 20110027774 and 20120006130) funded by the Ministry of Education, Science and Technology of the Republic of Korea.

\section{References}

1. Abbas A, Lichtman A and Pillai S (eds): Cellular and Molecular Immunology, 6th edition. Saunders Elsevier, Philadelphia, PA, 2007.

2. Aly HA: Cancer therapy and vaccination. J Immunol Methods 382: 1-23, 2012.

3. Hislop AD, Taylor GS, Sauce D and Rickinson AB: Cellular responses to viral infection in humans: lessons from Epstein-Barr virus. Annu Rev Immunol 25: 587-617, 2007

4. Finn OJ: Cancer immunology. N Engl J Med 358: 2704-2715, 2008.

5. Schreiber TH, Raez L, Rosenblatt JD and Podack ER: Tumor immunogenicity and responsiveness to cancer vaccine therapy: the state of the art. Semin Immunol 22: 105-112, 2010.

6. Bijker MS, Melief CJ, Offringa R and van der Burg SH: Design and development of synthetic peptide vaccines: past, present and future. Expert Rev Vaccines 6: 591-603, 2007.

7. Bode C, Zhao G, Steinhagen F, Kinjo T and Klinman DM: CpG DNA as a vaccine adjuvant. Expert Rev Vaccines 10: 499-511, 2011.

8. Klinman DM, Currie D, Gursel I and Verthelyi D: Use of CpG oligodeoxynucleotides as immune adjuvants. Immunol Rev 199: 201-216, 2004.

9. Krieg AM: CpG motifs in bacterial DNA and their immune effects. Annu Rev Immunol 20: 709-760, 2002.

10. Chu RS, Targoni OS, Krieg AM, Lehmann PV and Harding $\mathrm{CV}$ : CpG oligodeoxynucleotides act as adjuvants that switch on T helper 1 (Th1) immunity. J Exp Med 186: 1623-1631, 1997.

11. Carson DA and Raz E: Oligonucleotide adjuvants for T helper 1 (Th1)-specific vaccination. J Exp Med 186: 1621-1622, 1997.

12. Davis HL, Weeratna R, Waldschmidt TJ, Tygrett L, Schorr J and Krieg AM: CpG-DNA is a potent enhancer of specific immunity in mice immunized with recombinant hepatitis B surface antigen. J Immunol 160: 870-876, 1998.

13. Kim D, Rhee JW, Kwon S, Sohn WJ, Lee Y, et al: Immunostimulation and anti-DNA antibody production by backbone modified CpG-DNA. Biochem Biophys Res Commun 379: 362-367, 2009.

14. Lipford GB, Sparwasser T, Zimmermann S, Heeg K and Wagner H: CpG-DNA-mediated transient lymphadenopathy is associated with a state of Th1 predisposition to antigen-driven responses. J Immunol 165: 1228-1235, 2000.

15. Heikenwalder M, Polymenidou M, Junt T, Sigurdson C, Wagner H, et al: Lymphoid follicle destruction and immunosuppression after repeated $\mathrm{CpG}$ oligodeoxynucleotide administration. Nat Med 10: 187-192, 2004

16. Deng GM,Nilsson IM, Verdrengh M, Collins LV and Tarkowski A: Intra-articularly localized bacterial DNA containing $\mathrm{CpG}$ motifs induces arthritis. Nat Med 5: 702-705, 1999.

17. Lee KW, Jung J, Lee Y, Kim TY, Choi SY, et al: Immunostimulatory oligodeoxynucleotide isolated from genome wide screening of Mycobacterium bovis chromosomal DNA. Mol Immunol 43: 2107-2118, 2006

18. Henriksen-Lacey M, Korsholm KS Andersen P, Perrie Y and Christensen D: Liposomal vaccine delivery systems. Expert Opin Drug Deliv 8: 505-519, 2011.

19. Suzuki Y, Wakita D, Chamoto K, Narita Y, Tsuji T, et al: Liposome-encapsulated $\mathrm{CpG}$ oligodeoxynucleotides as a potent adjuvant for inducing type 1 innate immunity. Cancer Res 64: 8754-8760, 2004.

20. Kim D, Kwon S, Rhee JW, Kim KD, Kim YE, et al: Production of antibodies with peptide-CpG-DNA-liposome complex without carriers. BMC Immunol 12: 29, 2011.

21. Kim D, Kwon S, Ahn CS, Lee Y, Choi SY, Park J, Kwon HY and Kwon HJ: Adjuvant effect of liposome-encapsulated natural phosphodiester CpG-DNA. BMB Rep 44: 758-763, 2011.

22. Kim D, Kwon HJ and Lee Y: Activation of Toll-like receptor 9 and production of epitope specific antibody by liposome-encapsulated CpG-DNA. BMB Rep 44: 607-612, 2011.
23. Lee SA, Lee SY, Cho IH, Oh MA, Kang ES, et al: Tetraspanin TM4SF5 mediates loss of contact inhibition through epithelialmesenchymal transition in human hepatocarcinoma. J Clin Invest 118: 1354-1366, 2008.

24. Kwon S, Kim D, Park BK, Cho S, Kim KD, Kim YE, Park CS, Ahn HJ, Seo JN, Choi KC, Kim DS, Lee Y and Kwon HJ: Prevention and therapy of hepatocellular carcinoma by vaccination with TM4SF5 epitope-CpG-DNA-liposome complex without carriers. PLoS One 7: e33121, 2012.

25. Yoshiji H, Kuriyama S, Ways DK, Yoshii J and Miyamoto Y: Protein kinase $\mathrm{C}$ lies on the signaling pathway for vascular endothelial growth factor-mediated tumor development and angiogenesis. Cancer Res 59: 4413-4418, 1999.

26. Yoshiji H, Kuriyama S, Kawata M, Yoshii J, Ikenaka Y, et al: The angiotensin-I-converting enzyme inhibitor perindopril suppresses tumor growth and angiogenesis: possible role of the vascular endothelial growth factor. Clin Cancer Res 7: 1073-1078, 2001.

27. Richard K, Pierce SK and Song W: The agonists of TLR4 and 9 are sufficient to activate memory $\mathrm{B}$ cells to differentiate into plasma cells in vitro but not in vivo. J Immunol 181: 1746-1752, 2008.

28. McHeyzer-Williams LJ and McHeyzer-Williams MG: Antigenspecific memory B cell development. Annu Rev Immunol 23: 487-513, 2005.

29. Hayakawa K, Ishii R, Yamasaki K, Kishimoto T and Hardy RR: Isolation of high-affinity memory B cells: phycoerythrin as a probe for antigen-binding cells. Proc Natl Acad Sci USA 84: 1379-1383, 1987.

30. Ben-Yedidia T and Arnon R: Epitope-based vaccine against influenza. Expert Rev Vaccines 6: 939-948, 2007.

31. Ben-Yedidia T and Arnon R: Design of peptide and polypeptide vaccines. Curr Opin Biotechnol 8: 442-448, 1997.

32. Müller-Pillasch F, Wallrapp C, Lacher U, Friess H, Büchler M, Adler G and Gress TM: Identification of a new tumour-associated antigen TM4SF5 and its expression in human cancer. Gene 208: 25-30, 1998.

33. Lee SA, Ryu HW, Kim YM, Choi S, Lee MJ, et al: Blockade of four-transmembrane L6 family member 5 (TM4SF5)-mediated tumorigenicity in hepatocytes by a synthetic chalcone derivative. Hepatology 49: 1316-1325, 2009.

34. Lekishvili T, Fromm E, Mujoomdar M and Berditchevski F: The tumour-associated antigen L6 (L6-Ag) is recruited to the tetraspanin-enriched microdomains: implication for tumor cell motility. J Cell Sci 121: 685-694, 2008.

35. Plotkin SA: Vaccines: correlates of vaccine-induced immunity. Clin Infect Dis 47: 401-409, 2008.

36. Galli G, Medini D, Borgogni E, Zedda L, Bardelli M, Malzone C, Nuti S, Tavarini S, Sammicheli C, Hilbert AK, Brauer V, Banzhoff A, Rappuoli R, Del Giudice G and Castellino F: Adjuvanted $\mathrm{H} 5 \mathrm{~N} 1$ vaccine induces early $\mathrm{CD}^{+} \mathrm{T}$ cell response that predicts long-term persistence of protective antibody levels. Proc Natl Acad Sci USA 106: 3877-3882, 2009.

37. Vieira P and Rajewsky K: Persistence of memory B cells in mice deprived of T cell help. Int Immunol 2: 487-494, 1990.

38. Cancro MP: The persistence of memory: a unique niche for $\mathrm{IgG}$ memory B cells. Proc Natl Acad Sci USA 107: 12737-12738, 2010.

39. Bernasconi NL, Onai N and Lanzavecchia A: A role for Toll-like receptors in acquired immunity: up-regulation of TLR9 by BCR triggering in naive $\mathrm{B}$ cells and constitutive expression in memory B cells. Blood 101: 4500-4504, 2003.

40. Chiriva-Internati M, Yu Y, Mirandola L, Jenkins MR, Chapman C, Cannon M, Cobos E and Kast WM: Cancer testis antigen vaccination affords long-term protection in a murine model of ovarian cancer. PLoS One 5: e10471, 2010.

41. Cerkovnik P, Novakovic BJ, Stegel V and Novakovic S: Tumor vaccine composed of C-class $\mathrm{CpG}$ oligodeoxynucleotides and irradiated tumor cells induces long-term antitumor immunity. BMC Immunol 11: 45, 2010.

42. Chikh G and Schutze-Redelmeier MP: Liposomal delivery of CTL epitopes to dendritic cells. Biosci Rep 22: 339-353, 2002.

43. Chang JS, Choi MJ, Cheong HS and Kim K: Development of Th1-mediated $\mathrm{CD}^{+}$effector T cells by vaccination with epitope peptides encapsulated in $\mathrm{pH}$-sensitive liposomes. Vaccine 19: 3608-3614, 2001

44. Gursel I, Gursel M, Ishii KJ and Klinman DM: Sterically stabilized cationic liposomes improve the uptake and immunostimulatory activity of CpG oligonucleotides. J Immunol 167: 3324-3328, 2001. 